Ivana Sestak, Jack Cuzick, Queen Mary University; Mitch Dowsett, Elena Lopez-Knowles, Royal Marsden Hospital, London, United Kingdom; Martin Filipits, Peter Dubsky, Michael Gnant, Medical University of Vienna; Christian Fesl, Austrian Breast and Colorectal Cancer Study Group, Vienna, Austria; John Wayne Cowens, Sean Ferree, NanoString Technologies, Seattle, WA; and Carl Shaper, MyRAQA, Redwood Shores, CA.

Published online ahead of print at www.jco.org on October 20, 2014

Supported by Breakthrough Breast Cancer, National Institute for Health Research Biomedical Research Centre at The Royal Marsden Hospital, and Grant No. C569-10404 from the Cancer Research United Kingdom program.

Presented at the 36th Annual San Antonio Breast Cancer Symposium, San Antonio, TX, December 10-14, 2013.

Terms in blue are defined in the glossary, found at the end of this article and online at www.jco.org.

Authors' disclosures of potential conflicts of interest and author contributions are found at the end of this article.

Clinical trial information: ISRCTN18233230, NCT00291759.

Corresponding author: Ivana Sestak, PhD, Centre for Cancer Prevention, Wolfson Institute of Preventive Medicine, Queen Mary University London, Charterhouse Square, London EC1M 6BQ, United Kingdom; e-mail: i.sestak@qmul.ac.uk.

C 2014 by American Society of Clinical Oncology

0732-183X/15/3308w-916w/\$20.00

DOI: 10.1200/JCO.2014.55.6894

\title{
Prediction of Late Distant Recurrence After 5 Years of Endocrine Treatment: A Combined Analysis of Patients From the Austrian Breast and Colorectal Cancer Study Group 8 and Arimidex, Tamoxifen Alone or in Combination Randomized Trials Using the PAM50 Risk of Recurrence Score
}

Ivana Sestak, Jack Cuzick, Mitch Dowsett, Elena Lopez-Knowles, Martin Filipits, Peter Dubsky, John Wayne Cowens, Sean Ferree, Carl Schaper, Christian Fesl, and Michael Gnant

See accompanying article on page 823

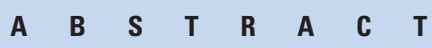

\section{Purpose}

We have previously shown that the PAM50-based risk of recurrence (ROR) score is significantly correlated with distant recurrence in both the translational research cohort within the Arimidex, Tamoxifen Alone or in Combination (ATAC) trial (TransATAC) and Austrian Breast and Colorectal Cancer Study Group 8 (ABCSG 8) randomized trials. Here, we focus on the ROR score for predicting distant recurrence after 5 years of follow-up in a combined analysis of these two randomized trials.

\section{Methods}

Long-term follow-up data and tissue samples were obtained from 2,137 postmenopausal women with hormone receptor-positive early-stage breast cancer from the ABCSG 8 and TransATAC trials. We used Cox proportional hazard regression models to determine the prognostic value of ROR for distant recurrence beyond 5 years in the combined data set.

\section{Results}

A total of 2,137 women who did not have a recurrence 5 years after diagnosis were included in the combined analyses. The Clinical Treatment Score (CTS) was the strongest prognostic factor 5 years after diagnosis (univariable: likelihood ratio $[L R] \chi^{2}=94.12$, bivariable: $L R \chi^{2}=61.43$ ). The ROR score was significantly prognostic by itself in years 5 to 10 . In the node-negative/human epidermal growth factor receptor 2-negative subgroup, more prognostic value for late distant recurrence was added by the ROR score compared with the CTS.

\section{Conclusion}

The ROR score added clinically meaningful prognostic information to the CTS in all patients and all subgroups in the late follow-up period. These results suggest that the ROR score may be helpful for separating patients into risk groups who could be spared or potentially benefit from extended hormonal therapy beyond 5 years of treatment.

J Clin Oncol 33:916-922. (C) 2014 by American Society of Clinical Oncology

\section{INTRODUCTION}

Women with estrogen receptor (ER) -positive tumors remain at risk for late recurrences, with the annual rate in excess of $2 \%$ for at least 15 years, even after 5 years of tamoxifen therapy. ${ }^{1}$ Currently, it is not possible to identify a group of women who can be considered as cured after the initial 5 years of endocrine therapy. ${ }^{2,3}$ Most of the studies of prevention of late relapse have been performed with women who received tamoxifen as initial endocrine therapy, ${ }^{4,5}$ and there are only a few reports with women who initially received an aromatase inhibitor.

It has been reported that women with highly proliferative tumors (a high mitotic kinase score) and a high estrogen-related score were at greater risk of late recurrence. ${ }^{6}$ The Breast Cancer Index (BCI) showed prognostic ability to assess early and late distant recurrence. ${ }^{7}$ Sgroi et $\mathrm{al}^{8}$ reported on the comparative performance of the BCI versus immunohistochemical 4 markers and Oncotype Dx recurrence score (RS) for 
late recurrence and found that the BCI is a strong prognostic factor in predicting late recurrence. Dubsky et $\mathrm{al}^{9}$ reported on the EndoPredict test, which stratifies patients into low- and high-risk groups for late recurrence (Appendix Table A1, online only).

The risk of recurrence (ROR) score has previously been shown to add prognostic information not found in standard markers. ${ }^{10,11}$ In the translational research cohort within the Arimidex, Tamoxifen Alone or in Combination (ATAC) trial (TransATAC), ${ }^{12}$ the performance of the ROR score was compared with that of the RS and immunohistochemical 4 for distant recurrence in 1,007 postmenopausal women, and results showed that the ROR added more prognostic information in endocrine-treated women with node-negative disease than the RS. Similarly, the Austrian Breast and Colorectal Cancer Study Group 8 (ABCSG 8) trial $^{13}$ showed that the ROR score predicted the risk of distant recurrence in 1,478 postmenopausal women with ER-positive early-stage breast cancer. It is important to determine to what extent the ROR score can help predict late recurrence, specifically beyond 5 years after diagnosis. Here, we combine the data from the TransATAC and ABCSG 8 trials and investigate the extent to which the ROR score predicts for distant recurrence exclusively in years 5 to 10 after diagnosis.

\section{METHODS}

The ATAC trial evaluated the efficacy and safety of anastrozole versus tamoxifen given for 5 years in postmenopausal women with localized breast cancer. ${ }^{14}$ The TransATAC substudy collected formalin-fixed, paraffin embedded blocks from hormone receptor-positive breast cancers in a subset of women randomly assigned to the monotherapy arms of the ATAC trial. ${ }^{15}$ The ABCSG 8 trial was a randomized, open-label trial comparing 5 years of tamoxifen with 2 years of tamoxifen followed by 3 years of anastrozole in postmenopausal women with hormone receptor-positive breast cancer, for whom formalinfixed, paraffin embedded blocks from the original tumors were collected to extract RNA and for use in a subsequent PAM50 analysis. ${ }^{16}$ Both trials were performed in accordance with the Declaration of Helsinki (1996 revision), under the principles of good clinical practice. The ATAC trial is registered as an International Standard Randomized Controlled Trial (ISRCTN18233230) and the ABCSG 8 trial is registered under the Clinical Trial Registry (NCT00291759).

The Clinical Treatment Score (CTS) contains information on nodal status, tumor size, grade, age, and treatment and was developed on the TransATAC data set. ${ }^{17}$ The laboratory methods for the original ROR score have been described in detail previously. ${ }^{10,17,18}$ Briefly, the expression levels for 50 classifier genes and eight housekeeping genes were measured by using the nCounter platform (NanoString Technologies, Seattle, WA), which gives a ROR score between zero and 100 that is indicative of the probability of distant recurrence. After normalization, the expression profile of the 50 classifier genes for each sample was used to determine the intrinsic subtype of the tumor. A 46-gene subset of the PAM50 genes plus tumor size was used to calculate a predefined ROR score, which performed as well as the ROR score that was based on the 50 -gene set. ${ }^{18}$ Risk stratification by using the ROR score was based on the predicted distant recurrence risk at 10 years $(<10 \%$ : low-risk group, ROR 0 to 26 ; $10 \%$ to $20 \%$ : intermediate-risk group, ROR 26 to 68 ; $>20 \%$ : high-risk group, ROR $>68$ ).

The primary objective of this study was to determine whether the ROR score provides prognostic information in the period beginning 5 years after diagnosis. The time from 5 years after diagnosis to the first distant recurrence after 5 years was the prospectively defined primary end point. Death before distant recurrence was treated as a censoring event. The association between ROR score and distant recurrence after 5 years of follow-up was assessed by using hazard ratios (HRs) derived from Cox proportional hazards regression models with associated 95\% CIs. For bivariable analyses, the ROR score was added separately to the CTS to determine the added prognostic information in that score. Changes in likelihood ratio $\chi^{2}\left(\operatorname{LR} \chi^{2}\right)$ values were used to measure and compare the relative amount of information of one score compared with the other. Survival curves were estimated by using the KaplanMeier method. All curves were truncated at 10 years of follow-up because differential follow-up was available for the two trials thereafter. However, overall HRs are presented for all events in both trials. The Net Reclassification Index (NRI) was used to determine the prognostic improvement by ROR beyond that of the CTS. ${ }^{19,20} P$ values were two-sided based on normal approximation, and all CIs were at the 95\% level. Analyses were performed by using STATA version 12.1 (STATA, College Station, TX).

\section{RESULTS}

The two trials were combined in this analysis and baseline characteristics are shown in Table 1, and further prognostic baseline factors according to ROR risk group are shown in Appendix Table A2 (online only). For this analysis, women who had a recurrence in the first 5 years were excluded; thus, data from both trials included only postmenopausal women with hormone receptor-positive breast cancer who received 5 years of endocrine treatment and who did not have a recurrence in the first 5 years $(\mathrm{N}=2,137$ [1,275 from ABCSG 8; 862 from TransATAC]). The mean ROR score for those women who were excluded from this analysis (who had a recurrence during the first 5 years) was significantly higher compared with the scores for those who did not have a recurrence in the first 5 years (53.57 [standard deviation, 20.4] $v 41.89$ [standard deviation, 19.5]; $P<.001$ ). The median follow-up for this analysis was 10 years. ${ }^{21,22}$ There were 148 distant recurrences beyond 5 years of follow-up. This analysis focuses only on the prognostic information obtained for 5 years after diagnosis. Data are presented for all patients, node-negative patients, nodepositive patients, and human epidermal growth factor receptor 2 (HER2) -negative patients.

There was a significantly higher rate of distant recurrence in years 5 to 10 in the TransATAC trial when compared with the ABCSG 8 trial $(P<.001)$. The TransATAC trial had significantly more women with large tumors $(P<.001)$, poorly differentiated tumors (none in the ABCSG 8 trial), and four or more positive nodes. Additional baseline characteristics for both populations have been described in detail previously. ${ }^{16,17}$ An analysis has been performed excluding grade 3 tumors from the TransATAC data set. The omission of these tumors did not substantially change the results (data not shown). A total of 1,530 women $(73.8 \%)$ had a luminal A breast cancer subtype and 542 women $(26.2 \%)$ had a luminal B breast cancer subtype; those with a luminal B subtype had a 2.9 times higher risk of distant recurrence (HR, 2.89; 95\% CI, 2.07 to $4.02 ; P<.001$ ).

In the overall population, CTS added more prognostic information for distant recurrence 5 years after diagnosis in the univariable analysis $\left(\operatorname{LR} \chi^{2}=94.12\right)$ and when added to the ROR score $\left(\operatorname{LR} \chi^{2}=\right.$ 61.43; Table 2). The ROR score also added significant prognostic information for this time period but somewhat less than the CTS (univariable LR $\chi^{2}=67.94$; bivariable LR $\chi^{2}=35.25$ ). Figure 1 shows Kaplan-Meier curves for the separation of ROR scores into low-, intermediate-, and high-risk groups based on the 10-year distant recurrence risk of less than $10 \%, 10 \%$ to $20 \%$, and more than $20 \%$. Women categorized into the high-risk group had 16.6\% (95\% CI, $13.1 \%$ to $20.9 \%$ ) risk of distant recurrence in years 5 to 10 , those in the intermediate-risk group had a risk of $8.3 \%$ (95\% CI, 6.1\% to $11.2 \%$ ), and those in the low-risk group had a risk of $2.4 \%(95 \% \mathrm{CI}, 1.6 \%$ to 


\begin{tabular}{|c|c|c|c|c|c|}
\hline \multirow[b]{2}{*}{ Characteristic } & \multicolumn{2}{|c|}{ TransATAC $(n=862)$} & \multicolumn{2}{|c|}{ ABCSG $8(n=1,275)$} & \multirow[b]{2}{*}{$P$} \\
\hline & No. & $\%$ & No. & $\%$ & \\
\hline Treatment (tamoxifen $v$ anastrozole) & $412 \vee 450$ & & $629 \vee 646$ & & .5 \\
\hline Nodal status (negative $v$ positive) & $647 \vee 215$ & $75.1 \vee 24.9$ & $933 \vee 342$ & $73.2 \vee 26.8$ & .3 \\
\hline Node positive (one to three nodes) & 180 & 20.9 & 307 & 24.1 & \\
\hline Node positive (four or more nodes) & 35 & 4.1 & 35 & 2.8 & \\
\hline Tumor size, mm & & & & & $<.001$ \\
\hline Mean & & & & & \\
\hline Standard deviation & & & & & \\
\hline$\leq 10$ & 128 & 14.8 & 239 & 18.7 & \\
\hline $10-20$ & 459 & 53.3 & 699 & 54.8 & \\
\hline $20-30$ & 210 & 24.4 & 283 & 22.2 & \\
\hline$>30$ & 65 & 7.5 & 54 & 4.2 & \\
\hline Age ( $\leq 65 v>65$ years $)$ & $504 \vee 358$ & $58.5 \vee 41.5$ & $774 \vee 501$ & $60.7 \vee 39.3$ & .3 \\
\hline \multicolumn{6}{|l|}{ Differentiation } \\
\hline Well & 195 & 22.6 & 242 & 19.0 & .04 \\
\hline Moderate & 519 & 60.2 & 1033 & 81.0 & $<.001$ \\
\hline Poor & 148 & 17.2 & - & & - \\
\hline Distant recurrence (years 5 to 10 ) & 80 & 9.3 & 68 & 5.3 & $<.001$ \\
\hline
\end{tabular}

3.5\%; Fig 1). Women in the ROR high-risk group had a 6.9 times higher risk of late distant recurrence (HR, 6.90; 95\% CI, 4.54 to 10.47), and those in the intermediate-risk group had a 3.3 times higher risk of late distant recurrence (HR, 3.26; 95\% CI, 2.07 to 5.13) compared with those in the low-risk group. Figure 2 shows annual hazard rate curves with corresponding 95\% CIs for the three risk groups. Those in the low-risk group showed stable annual hazard rates under $1 \%$ per year between 5 and 10 years, whereas those in the intermediate-risk group showed an increase from $1 \%$ up to $2 \%$ at year 8 (Fig 2). Women in the high-risk group had an increasing annual hazard rate peaking at $4 \%$ at 6.9 years of follow-up and then stabilized at around 3\% per year thereafter.

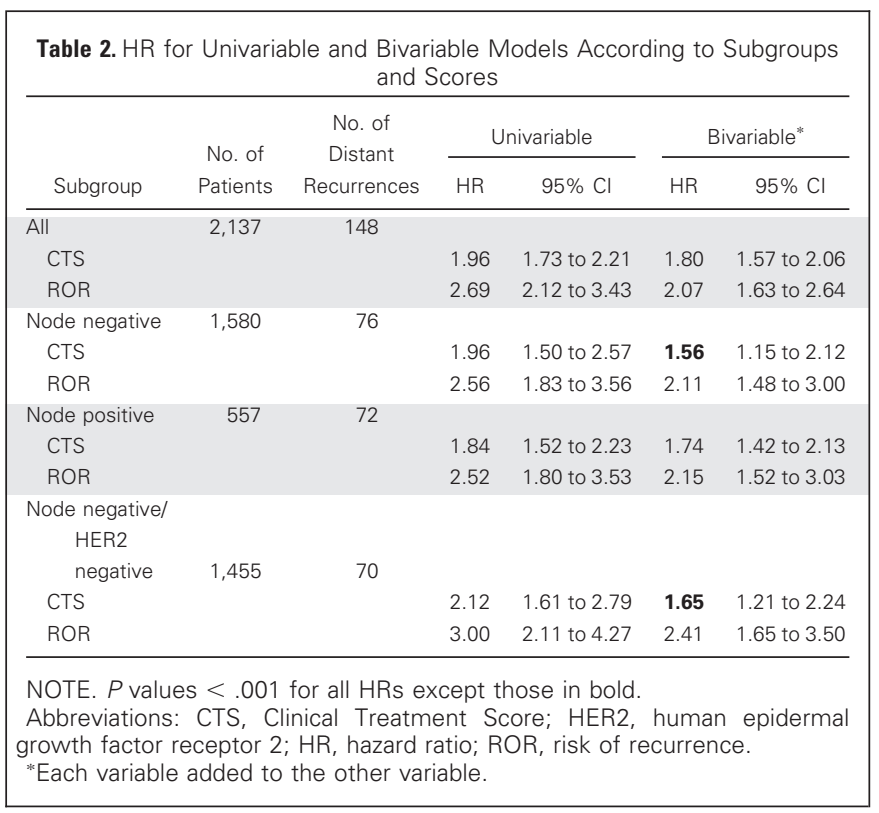

Results for the main subgroups according to nodal and HER2 status are shown in Table 2 and Appendix Table A3 (online only). In node-negative patients $(n=1,580)$, the ROR score added more prognostic information than the CTS in both the univariable and the bivariable analyses (univariable LR $\chi^{2}=30.95 v \operatorname{LR} \chi^{2}=21.48$; bivariable $\operatorname{LR} \chi^{2}=17.25 v \operatorname{LR} \chi^{2}=7.79$ ). A similar picture was seen for the node-negative/HER2-negative subgroup for which more prognostic value for late distant recurrence was added by the ROR score. Women in the ROR low-risk group had a $2 \%$ (95\% CI, 1.3\% to 3.2\%) risk of distant recurrence by 10 years compared with similar 10-year distant recurrence rates for those in the intermediate-risk group (9.0\%; 95\% CI, 6.3\% to $13.0 \%)$ and high-risk group (11.5\%; 95\% CI, $6.8 \%$ to $19.0 \%$; Fig 3 and Appendix Table A3). In all, 557 women had

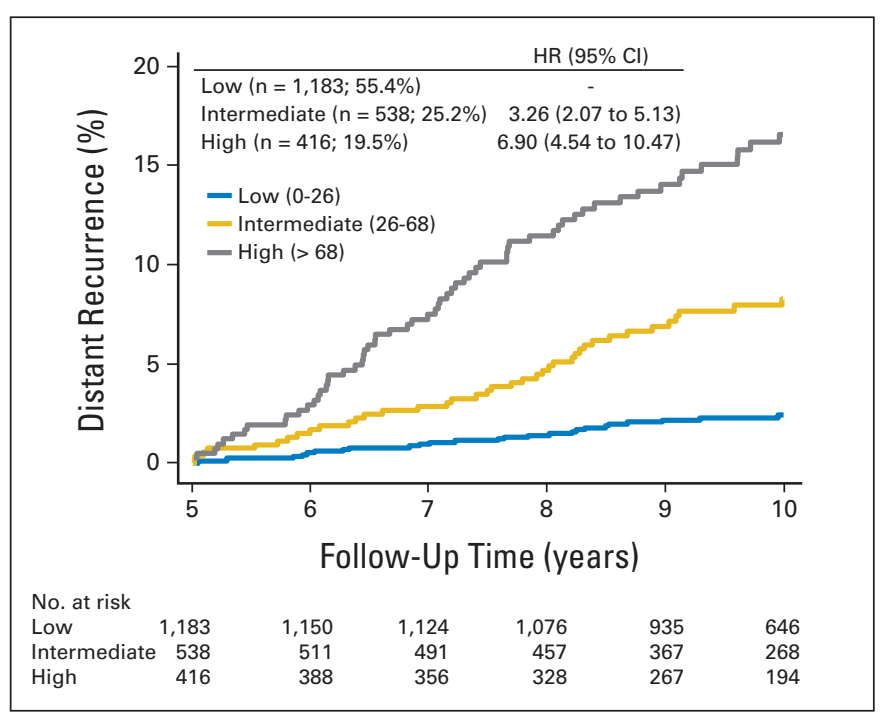

Fig 1. Kaplan-Meier curve for distant recurrence in years 5 to 10 in all patients according to risk of recurrence risk groups. HR, hazard ratio. 


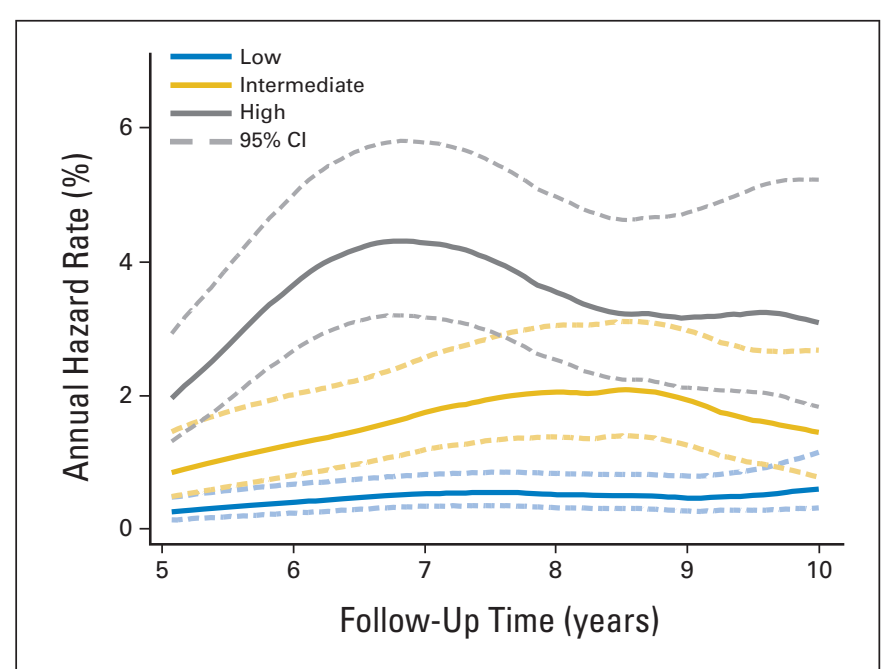

Fig 2. Annual hazard rate curve for all patients according to risk of recurrence groups.

a node-positive tumor, and in those, CTS added most prognostic information univariately $\left(\operatorname{LR} \chi^{2}=35.60\right)$ and when added to the ROR score $\left(\operatorname{LR} \chi^{2}=25.67\right)$. The ROR score added somewhat less but still significant prognostic information for distant recurrence in this subgroup (Table 2). 24.6\% of women with node-positive disease were categorized into the low-risk ROR group with a distant recurrence risk of only $3.3 \%$ in the late follow-up period (Appendix Table A3). Overall, the effect size for the ROR score in the bivariable analyses was similar across all subgroups (Table 2).

The correlation between the CTS and ROR was weak $(r=0.36)$. Agreement between the ROR score and CTS for separating patients into low-, intermediate-, and high-risk groups is shown in Table 3. The number of women categorized into the low-risk group was similar for the two scores ( $55.4 \% v 53.3 \%)$. However, the CTS categorized overall more women into the intermediate-risk group $(32.4 \%)$ than

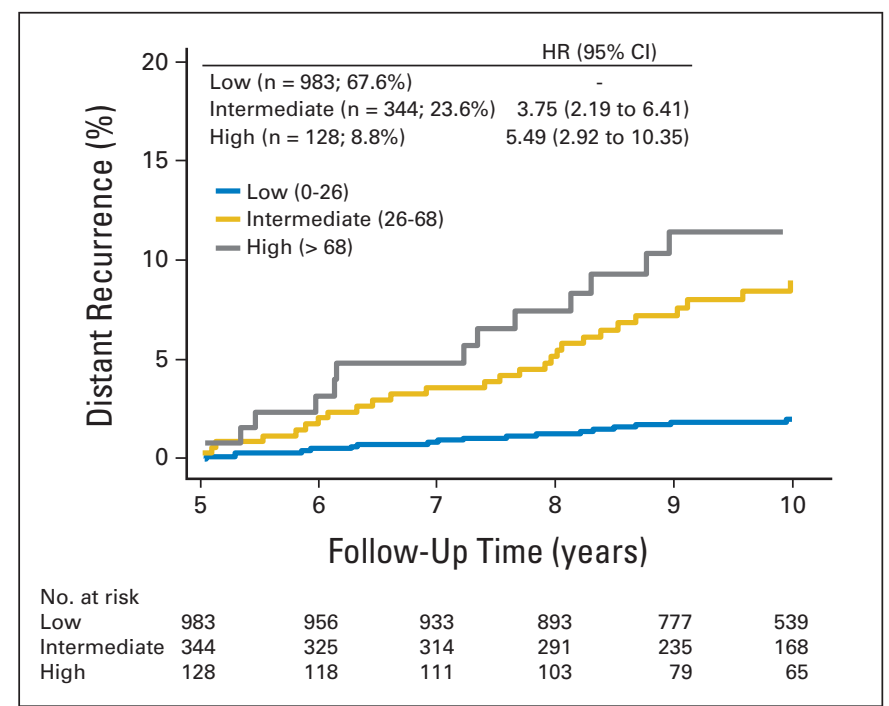

Fig 3. Kaplan-Meier curve for distant recurrence in years 5 to 10 in nodenegative/human epidermal growth factor receptor 2-negative patients according to risk of recurrence risk groups. HR, hazard ratio. the ROR score $(25.2 \%)$, which categorized more women as high risk (19.5\% ROR $v$ 14.3\% CTS; Table 3). Furthermore, Appendix Fig A1 (online only) shows the reclassification of distant recurrence and nonevents by ROR or CTS plus ROR versus CTS alone. For those with distant recurrence, the ROR score classified 32 women into higherrisk and 21 into lower-risk categories compared with the CTS alone. This translates into a net reclassification of $7.4 \%$ for women with distant recurrence. For nonevents, the reclassification by ROR was small $(1.5 \%)$. The overall NRI for ROR versus CTS was $5.97 \%$, which was not significant $(P=.3)$. The addition of ROR to the CTS improved the classification for distant recurrence (14 women into higher-risk $v 3$ women into lower-risk groups; net reclassification of 7.4\%) compared with CTS alone, but a net loss was observed for women with nonevents (123 women into higher-risk $v 161$ into lower-risk groups; net reclassification, 1.9\%). For this comparison, a significant NRI of $9.34 \%$ was observed $(P=.001$; Appendix Fig A1). Similar results were seen for women with node-negative disease (data not shown).

\section{DISCUSSION}

It is well known that recurrence risk extends for at least 20 years in women with hormone receptor-positive early-stage breast cancer treated with 5 years of endocrine therapy. ${ }^{23}$ Continued (extended) adjuvant treatment beyond 5 years reduces recurrence rates but is unlikely to be significantly beneficial to all patients individually. It is therefore crucial to identify molecular markers that predict late recurrence. The analyses of combined data from the TransATAC and ABCSG 8 trials showed that the ROR score added significant prognostic information for late distant recurrence in women with hormone receptor-positive early-stage breast cancer who did not receive chemotherapy. Predefined risk stratification showed significant differences between ROR-defined risk groups with respect to 10-year late distant recurrence.

The ROR score has previously been shown to add prognostic information for recurrence in the two trials of endocrine-treated patients. ${ }^{11,18}$ The ROR score was able to predict the risk of distant recurrence in postmenopausal women with early hormone receptor-positive early-stage breast cancer. $^{22}$ In the TransATAC trial, the ROR score added more prognostic information than the Oncotype RS. ${ }^{18}$ In this combined analysis, the CTS was the stronger prognostic score for late distant recurrence overall and for the node-positive subgroup. In contrast, the ROR score was the stronger predictor of late distant recurrence for patients with node-negative and node-negative/HER2-negative disease, who may be spared further endocrine therapy, specifically those who were categorized into the low-risk group by the ROR score.

The ROR score provided clinically useful prognostic information, predicting risk of late distant recurrence beyond that of classical clinical markers in all subgroups. Of note is that $24.6 \%$ of women with node-positive disease were categorized into the ROR low-risk group with a distant recurrence risk of only $3.3 \%$ in years 5 to 10 . Given this low risk of distant recurrence at both early and late follow-up periods, the indication for adjuvant chemotherapy and the extension of endocrine therapy beyond 5 years are both questionable. Concerning the node-negative population with HER2-negative disease, large tumor size and premenopausal status at diagnosis have been suggested as factors to select women for extended adjuvant endocrine treatment. ${ }^{24-26}$ 


\begin{tabular}{|c|c|c|c|c|c|c|c|c|}
\hline \multirow[b]{3}{*}{ Risk Group } & \multicolumn{8}{|c|}{ CTS } \\
\hline & \multicolumn{2}{|c|}{ Low } & \multicolumn{2}{|c|}{ Intermediate } & \multicolumn{2}{|c|}{ High } & \multicolumn{2}{|c|}{ Total } \\
\hline & No. & $\%$ & No. & $\%$ & No. & $\%$ & No. & $\%$ \\
\hline \multicolumn{9}{|l|}{ ROR } \\
\hline Low & 855 & & 287 & & 41 & & 1,183 & 55.4 \\
\hline Intermediate & 216 & & 252 & & 70 & & 538 & 25.2 \\
\hline High & 68 & & 154 & & 194 & & 416 & 19.5 \\
\hline Total & 1,139 & 53.3 & 693 & 32.4 & 305 & 14.3 & 2,137 & \\
\hline \multicolumn{9}{|l|}{ CTS plus ROR } \\
\hline Low & 1,055 & & 139 & & 0 & & 1,194 & 55.8 \\
\hline Intermediate & 84 & & 501 & & 25 & & 610 & 28.5 \\
\hline High & 0 & & 53 & & 280 & & 333 & 15.6 \\
\hline Total & 1,139 & 53.3 & 693 & 32.4 & 305 & 14.3 & 2,137 & \\
\hline
\end{tabular}

NOTE. Cutoffs according to 10-year distant recurrence risk: low, $<10 \%$; intermediate, $10 \%$ to $20 \%$; high, $>20 \%$.

Abbreviations: CTS, Clinical Treatment Score; ROR, risk of recurrence.

Our results show that women with node-negative disease categorized into the ROR low-risk group have an extremely low rate of late distant recurrence despite some of them having large tumors, which challenges the indication for additional therapy. In contrast, women with node-negative disease categorized into the high-risk group by the ROR score might benefit from additional endocrine therapy, but this needs further confirmation because the ROR score is a prognostic and not predictive marker.

Strengths of this analysis included its large sample size $(\mathrm{N}=2,137)$, long follow-up with a median of 10 years, and a patient population that came from two well-characterized registration clinical trials using tamoxifen and anastrozole. One limitation was that none of these women received chemotherapy as part of their initial treatment, and therefore we are unable to analyze the prognostic value of the ROR score for late distant recurrence in this group of patients. Baseline characteristics were somewhat different between the two trials. Women in the ABCSG 8 trial had an overall low-to-intermediate risk of late distant recurrence, whereas those in the TransATAC trial showed an increased risk, which is explained by larger tumor size, the inclusion of grade 3 tumors (none in the ABCSG 8 trial), and the presence of more women with more than four positive nodes. Analyses with exploratory exclusion of grade 3 tumors from the TransATAC trial showed similar results. The combined analysis offered a unique opportunity to investigate the prognostic value of the ROR score in this clinically relevant population.

In summary, we showed that the ROR score provided additional clinically meaningful prognostic information for late distant recurrence beyond standard clinical variables (CTS) and was able to discriminate patients into low- and high-risk groups in this large combined data set. The ROR score has been validated in several trials, ${ }^{11,12,18}$ and the results presented here may help to identify women who are at high risk of late distant recurrence and who may benefit from extended endocrine treatment beyond 5 years. Conversely, the results show that the ROR score is able to identify women who are at sufficiently low risk of late distant recurrence, even in women with node-positive disease, so that they may be spared prolonged and/or additional endocrine treatment and, therefore, overtreatment.

\section{AUTHORS' DISCLOSURES OF POTENTIAL CONFLICTS OF INTEREST}

Although all authors completed the disclosure declaration, the following author(s) and/or an author's immediate family member(s) indicated a financial or other interest that is relevant to the subject matter under consideration in this article. Certain relationships marked with a " $U$ " are those for which no compensation was received; those relationships marked with a "C" were compensated. For a detailed description of the disclosure categories, or for more information about ASCO's conflict of interest policy, please refer to the Author Disclosure Declaration and the Disclosures of Potential Conflicts of Interest section in Information for Contributors. Employment or Leadership Position: John Wayne Cowens, NanoString Technologies (C); Sean Ferree, NanoString Technologies (C) Consultant or Advisory Role: Jack Cuzick, NanoString Technologies (C); Mitch Dowsett, NanoString Technologies (C), Genoptix (C); Martin Filipits, AstraZeneca (C), NanoString Technologies (C), Sividon Diagnostics (C); Peter Dubsky, Sividon Diagnostics (C), Genomic Health (C), NanoString Technologies (U), Agendia (U); Carl Schaper, NanoString Technologies (C); Michael Gnant, Accelsiors (C), Novartis (C), AstraZeneca (C) Stock Ownership: John Wayne Cowens, NanoString Technologies; Sean Ferree, NanoString Technologies Honoraria: Martin Filipits,

AstraZeneca, Eli Lilly, Novartis, Pfizer, Roche, Sividon Diagnostics; Peter Dubsky, Sividon Diagnostics, Genomic Health; Michael Gnant, Amgen, Novartis, GlaxoSmithKline, AstraZeneca, Roche, NanoString Technologies Research Funding: Jack Cuzick, AstraZeneca; Mitch Dowsett, AstraZeneca; Peter Dubsky, Sividon Diagnostics, Agendia; Michael Gnant, sanofi-aventis, Novartis, Roche, GlaxoSmithKline, Pfizer, Smiths Medical Expert Testimony: None Patents, Royalties, and Licenses: None Other Remuneration: None

\section{AUTHOR CONTRIBUTIONS}

Conception and design: Ivana Sestak, Jack Cuzick, Mitch Dowsett, Martin Filipits, Peter Dubsky, John Wayne Cowens, Michael Gnant Collection and assembly of data: Jack Cuzick, Elena Lopez-Knowles, Sean Ferree, Michael Gnant

Data analysis and interpretation: Ivana Sestak, Jack Cuzick, Mitch Dowsett, Martin Filipits, Peter Dubsky, John Wayne Cowens, Sean Ferree, Carl Schaper, Christian Fesl, Michael Gnant

Manuscript writing: All authors

Final approval of manuscript: All authors 


\section{REFERENCES}

1. Saphner T, Tormey DC, Gray R: Annual hazard rates of recurrence for breast cancer after primary therapy. J Clin Oncol 14:2738-2746, 1996

2. [No authors listed]: Tamoxifen for early breast cancer: An overview of the randomised trials-Early Breast Cancer Trialists' Collaborative Group. Lancet 351:1451-1467, 1998

3. Early Breast Cancer Trialists' Collaborative Group: Tamoxifen for early breast cancer. Cochrane Database Syst Rev 1:CD000486, 2001

4. Goss PE: Preventing relapse beyond 5 years: The MA.17 extended adjuvant trial. Semin Oncol 33:S8-S12, 2006

5. Brewster AM, Hortobagyi GN, Broglio KR, et al: Residual risk of breast cancer recurrence 5 years after adjuvant therapy. J Natl Cancer Inst 100:11791183, 2008

6. Bianchini G, Pusztai L, Iwamoto $T$, et al: Molecular tumor characteristics influence adjuvant endocrine treatment outcome. Cancer Res 71:S1S7, 2011

7. Zhang Y, Schnabel CA, Schroeder BE, et al: Breast cancer index identifies early-stage estrogen receptor-positive breast cancer patients at risk for early- and late-distant recurrence. Clin Cancer Res 19:4196-4205, 2013

8. Sgroi DC, Sestak I, Cuzick J, et al: Comparative performance of Breast Cancer Index (BCl) vs. Oncotype Dx and IHC4 in the prediction of late recurrence in hormonal receptor-positive lymph node-negative breast cancer patients: A TransATAC Study. Cancer Res 72:S1-S9, 2012

9. Dubsky P, Brase JC, Jakesz R, et al: The EndoPredict score provides prognostic information on late distant metastases in ER+/HER2 - breast cancer patients. Br J Cancer 109:2959-2964, 2013

10. Parker JS, Mullins $M$, Cheang $M C$, et al: Supervised risk predictor of breast cancer based on intrinsic subtypes. J Clin Oncol 27:1160-1167, 2009

11. Nielsen TO, Parker JS, Leung $S$, et al: $A$ comparison of PAM50 intrinsic subtyping with immunohistochemistry and clinical prognostic factors in tamoxifen-treated estrogen receptor-positive breast cancer. Clin Cancer Res 16:5222-5232, 2010

12. Dowsett M, Sestak I, Lopez-Knowles E, et al: Comparison of PAM50 risk of recurrence score with oncotype DX and IHC4 for predicting risk of distant recurrence after endocrine therapy. J Clin Oncol 31:2783-2790, 2013

13. Gnant M, Filipits $M$, Greil R, et al: Predicting distant recurrence in receptor-positive breast cancer patients with limited clinicopathological risk: Using the PAM50 Risk of Recurrence score in 1478 postmenopausal patients of the ABCSG-8 trial treated with adjuvant endocrine therapy alone. Ann Oncol 25:339-345, 2014

14. Arimidex, Tamoxifen, Alone or in Combination (ATAC) Trialists' Group, Forbes JF, Cuzick J, et al: Effect of anastrozole and tamoxifen as adjuvant treatment for early-stage breast cancer: 100-month analysis of the ATAC trial. Lancet Oncol 9:45-53, 2008

15. Dowsett M, Allred C, Knox J, et al: Relationship between quantitative estrogen and progesterone receptor expression and human epidermal growth factor receptor 2 (HER-2) status with recurrence in the Arimidex, Tamoxifen, Alone or in Combination trial. J Clin Oncol 26:1059-1065, 2008

16. Dubsky PC, Jakesz R, Mlineritsch $B$, et al: Tamoxifen and anastrozole as a sequencing strategy: A randomized controlled trial in postmenopausal patients with endocrine-responsive early breast cancer from the Austrian Breast and Colorectal Cancer Study Group. J Clin Oncol 30:722-728, 2012

17. Cuzick J, Dowsett M, Pineda S, et al: Prognostic value of a combined estrogen receptor, progesterone receptor, Ki-67, and human epidermal growth factor receptor 2 immunohistochemical score and comparison with the Genomic Health recurrence score in early breast cancer. J Clin Oncol 29:4273-4278, 2011

18. Dowsett M, Lopez-Knowles E, Sidhu K, et al: Comparison of PAM50 risk of recurrence (ROR) score with OncotypeDx and IHC4 for predicting residual risk of RFS and distant-(D)RFS after endocrine therapy: A TransATAC study. Presented at the 34th Annual CTRC-AACR San Antonio Breast Cancer Symposium, San Antonio, TX, December 6-10, 2011

19. Pencina MJ, D'Agostino RB Sr, D'Agostino RB Jr, et al: Evaluating the added predictive ability of a new marker: From area under the ROC curve to reclassification and beyond. Stat Med 27:157-172, 2008

20. Pencina MJ, D'Agostino RB Sr, Steyerberg EW: Extensions of net reclassification improvement calculations to measure usefulness of new biomarkers. Stat Med 30:11-21, 2011

21. Cuzick J, Sestak I, Baum M, et al: Effect of anastrozole and tamoxifen as adjuvant treatment for early-stage breast cancer: 10-year analysis of the ATAC trial. Lancet Oncol 11:1135-1141, 2010

22. Gnant $M$, Filipits $M$, Mlineritsch $B$, et al: Clinical validation of the PAM50 risk of recurrence (ROR) score for predicting residual risk of distantrecurrence (DR) after endocrine therapy in postmenopausal women with $\mathrm{ER}+$ early breast cancer (EBC): An ABCSG study. Cancer Res 72, 2012 (suppl 3: abstr P2-10-02)

23. Esserman LJ, Moore DH, Tsing PJ, et al: Biologic markers determine both the risk and the timing of recurrence in breast cancer. Breast Cancer Res Treat 129:607-616, 2011

24. Goss PE, Ingle JN, Martino S, et al: Randomized trial of letrozole following tamoxifen as extended adjuvant therapy in receptor-positive breast cancer: Updated findings from NCIC CTG MA.17. J Natl Cancer Inst 97:1262-1271, 2005

25. Goss PE, Ingle JN, Martino S, et al: Impact of premenopausal status at breast cancer diagnosis in women entered on the placebo-controlled $\mathrm{NCIC}$ CTG MA17 trial of extended adjuvant letrozole. Ann Oncol 24:355-361, 2013

26. Mamounas EP, Jeong JH, Wickerham DL, et al: Benefit from exemestane as extended adjuvant therapy after 5 years of adjuvant tamoxifen: Intention-to-treat analysis of the National Surgical Adjuvant Breast and Bowel Project B-33 trial. J Clin Oncol 26:1965-1971, 2008 


\section{GLOSSARY TERMS}

anastrozole: a third-generation nonsteroidal aromatase inhibitor that prevents the conversion of androgen to estrogen in the peripheral tissues in postmenopausal women. Because hormonedependent breast cancer progresses with estrogen, anastrozole has been used in the treatment of breast cancer in postmenopausal women. See aromatase inhibitors.

Cox proportional hazards regression model: a statistical model for regression analysis of censored survival data, examining the relationship of censored survival distribution to one or more covariates. This model produces a baseline survival curve, covariate coefficient estimates with their standard errors, risk ratios, 95\% CIs, and significance levels.

estrogen receptor (ER): ligand-activated nuclear proteins, belonging to the class of nuclear receptors, present in many breast cancer cells that are important in the progression of hormone-dependent cancers. After binding, the receptor-ligand complex activates gene transcription. There are two types of estrogen receptors (ER $\alpha$ and $\mathrm{ER} \beta$ ). $\mathrm{ER} \alpha$ is one of the most important proteins controlling breast cancer function. $\mathrm{ER} \beta$ is present in much lower levels in breast cancer, and its function is uncertain. Estrogen receptor status guides therapeutic decisions in breast cancer. prognostic factor: a measurable patient characteristic that is associated with the subsequent course of disease (whether or not therapy is administered). The identification of a prognostic factor does not necessarily suggest a cause-and-effect relationship. However, within a suitable outcome model, the measurement of a prognostic factor contributes to an estimate of an outcome probability (eg, the probability of disease-free survival within a given time interval).

recurrence score: a number between 0 and 100 that corresponds to a specific likelihood of breast cancer recurrence within 10 years of initial diagnosis. The score is derived from a mathematical function combining the expression values of 16 breast cancer related genes and five reference genes. 


\section{Acknowledgment}

Published in memory of Wayne Cowens, MD, co-author and former chief medical officer at NanoString. This data is a testament to Dr Cowens' leadership, scientific contributions, and unwavering support for his colleagues throughout his esteemed career.

\section{Appendix}

\begin{tabular}{|c|c|c|c|}
\hline Score & Abbreviation & Details & Reference \\
\hline Clinical Treatment Score & CTS & $\begin{array}{l}\text { Includes information on nodal status, grade, tumor size, age, and treatment. Score } \\
\text { developed on TransATAC data. }\end{array}$ & Cuzick et al ${ }^{17}$ \\
\hline $\begin{array}{l}\text { Immunohistochemical } \\
\text { Score } 4\end{array}$ & $\mathrm{IHC} 4$ & $\begin{array}{l}\text { Includes information on ER, PgR, Ki-67, and HER2. Score developed on } \\
\text { TransATAC data. FFPE blocks used to extract RNA to perform IHC for ER, PgR, } \\
\text { Ki-67, HER2. }\end{array}$ & $\begin{array}{l}\text { Dowsett et al, }{ }^{15} \text { Cuzick et al, }{ }^{17} \\
\text { Zabaglo et al: J Clin Pathol } \\
\text { 63:800-804, } 2010\end{array}$ \\
\hline $\begin{array}{l}\text { Oncotype Dx Recurrence } \\
\text { Score }\end{array}$ & RS & $\begin{array}{l}\text { Twenty-one-gene-based expression profile score using qRT-PCR ( } 16 \text { cancer } \\
\text { genes, five housekeeping genes). FFPE blocks used to extract RNA. }\end{array}$ & $\begin{array}{l}\text { Paik et al: N Engl J Med 351: } \\
\text { 2817-2826, } 2004\end{array}$ \\
\hline $\begin{array}{l}\text { Prosigna Risk of Recurrence } \\
\text { Score }\end{array}$ & ROR & $\begin{array}{l}\text { Fifty gene-based expression profile score using qRT-PCR. FFPE blocks used to } \\
\text { extract RNA to perform analysis on nCounter system. }\end{array}$ & Dowsett et al ${ }^{12}$ \\
\hline Breast Cancer Index & $\mathrm{BCl}$ & $\begin{array}{l}\text { Multigene assay using qRT-PCR. Combination of two biomarkers: HOXB13/IL17BR } \\
\text { and molecular grade index. }\end{array}$ & Zhang et al, ${ }^{7}$ Sgroi et al ${ }^{8}$ \\
\hline EndoPredict & EPClin & $\begin{array}{l}\text { Twelve gene-based expression profile score using qRT-PCR (eight cancer genes, } \\
\text { four housekeeping genes). FFPE blocks used to extract RNA to perform } \\
\text { analysis. }\end{array}$ & Dubsky et $\mathrm{al}^{9}$ \\
\hline
\end{tabular}

\begin{tabular}{|c|c|c|c|}
\hline \multirow[b]{2}{*}{ Factor } & \multicolumn{3}{|c|}{ ROR (\%) } \\
\hline & Low & Intermediate & High \\
\hline \multicolumn{4}{|l|}{$\overline{\text { Grade }}$} \\
\hline Low & 28.6 & 13.4 & 6.5 \\
\hline Intermediate & 68.6 & 77.4 & 78.1 \\
\hline High & 2.8 & 9.5 & 15.4 \\
\hline Negative nodal status & 88.4 & 70.3 & 37.5 \\
\hline Tumor size $>2 \mathrm{~cm}$ & 16.7 & 35.1 & 53.6 \\
\hline Age $>65$ years & 34.1 & 44.4 & 52.2 \\
\hline
\end{tabular}


Sestak et al

\begin{tabular}{|c|c|c|c|c|c|}
\hline Variable & No. of Patients & $\mathrm{HR}$ & $95 \% \mathrm{Cl}$ & 10-Year Risk (\%) & $95 \% \mathrm{Cl}$ \\
\hline \multicolumn{6}{|l|}{ All patients } \\
\hline Low & 1,183 & Reference & & 2.4 & 1.6 to 3.5 \\
\hline Intermediate & 538 & 3.26 & 2.07 to 5.13 & 8.3 & 6.1 to 11.2 \\
\hline High & 416 & 6.90 & 4.54 to 10.47 & 16.6 & 13.1 to 20.9 \\
\hline \multicolumn{6}{|l|}{ Node negative } \\
\hline Low & 1,046 & Reference & & 2.3 & 1.5 to 3.5 \\
\hline Intermediate & 378 & 3.22 & 1.93 to 5.37 & 8.5 & 5.9 to 12.1 \\
\hline High & 156 & 4.26 & 2.33 to 7.78 & 9.3 & 5.5 to 15.5 \\
\hline \multicolumn{6}{|l|}{ HER2 negative } \\
\hline Low & 1,117 & Reference & & 2.2 & 1.4 to 3.3 \\
\hline Intermediate & 498 & 3.70 & 2.31 to 5.95 & 8.7 & 6.4 to 11.9 \\
\hline High & 359 & 7.23 & 4.61 to 11.32 & 16.2 & 12.5 to 20.9 \\
\hline \multicolumn{6}{|c|}{ Node negative/HER2 negative } \\
\hline Low & 983 & Reference & & 2.0 & 1.3 to 3.2 \\
\hline Intermediate & 344 & 3.75 & 2.19 to 6.41 & 9.0 & 6.2 to 13.0 \\
\hline High & 128 & 5.49 & 2.92 to 10.35 & 11.5 & 6.8 to 19.0 \\
\hline \multicolumn{6}{|l|}{ Node positive } \\
\hline Low & 137 & Reference & & 3.3 & 1.2 to 8.6 \\
\hline Intermediate & 160 & 3.16 & 1.04 to 9.61 & 7.8 & 4.4 to 13.8 \\
\hline High & 260 & 7.94 & 2.87 to 21.92 & 20.9 & 16.1 to 26.9 \\
\hline \multicolumn{6}{|c|}{ Node positive with one to three nodes } \\
\hline Low & 137 & Reference & & 3.3 & 1.2 to 8.6 \\
\hline Intermediate & 154 & 3.04 & 0.99 to 9.32 & 7.5 & 4.1 to 13.5 \\
\hline High & 196 & 7.37 & 2.63 to 20.65 & 19.6 & 14.4 to 26.5 \\
\hline \multicolumn{6}{|c|}{ Node positive with four or more nodes } \\
\hline Low & 0 & - & & - & \\
\hline Intermediate & 6 & Reference & & 16.7 & 2.5 to 72.7 \\
\hline High & 64 & 1.67 & 0.17 to 83.68 & 24.7 & 15.3 to 38.3 \\
\hline
\end{tabular}


Distant recurrence $(N=148)$

CTS

\begin{tabular}{cccc} 
ROR & Low & Intermediate & High \\
\hline Low & $(n=18)$ & $(n=14)$ & $(n=0)$ \\
Intermediate & $(n=7)$ & $(n=31)$ & $(n=7)$ \\
High & $(n=8)$ & $(n=17)$ & $(n=46)$ \\
\hline
\end{tabular}

Non-events ( $N=1,989)$

CTS

\begin{tabular}{cccc} 
ROR & Low & Intermediate & High \\
\hline Low & $(n=837)$ & $(n=273)$ & $(n=41)$ \\
Intermediate & $(n=209)$ & $(n=221)$ & $(n=63)$ \\
High & $(n=60)$ & $(n=137)$ & $(n=148)$ \\
\hline
\end{tabular}

reclassified into high risk

group by ROR

reclassified into lower

risk group by ROR
Distant recurrence $(N=148)$

CTS

\begin{tabular}{cccc} 
CTS plus ROR & Low & Intermediate & High \\
\hline Low & $(n=25)$ & $(n=3)$ & $(n=0)$ \\
Intermediate & $(n=8)$ & $(n=53)$ & $(n=0)$ \\
High & $(n=0)$ & $(n=6)$ & $(n=53)$ \\
\hline
\end{tabular}

Non-events ( $N=1,989$ )

CTS

\begin{tabular}{ccccc} 
CTS plus ROR & Low & Intermediate & High \\
\hline Low & $(n=1,030)$ & $(n=136)$ & $(n=0)$ \\
Intermediate & $(n=76)$ & $(n=448)$ & $(n=25)$ \\
High & $(n=0)$ & $(n=47)$ & $(n=227)$ \\
\hline
\end{tabular}

reclassified into high risk group

by CTS plus ROR

reclassified into lower risk group

by CTS plus ROR

Fig A1. Net Reclassification Index (NRI) for distant recurrence $(N=148)$ versus nonevents $(N=1,989)$ for all patients. Left panel: gray-shaded area represent patients reclassified

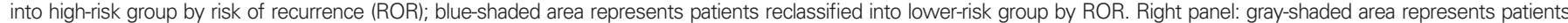

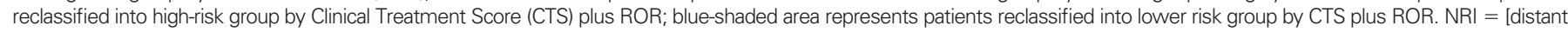

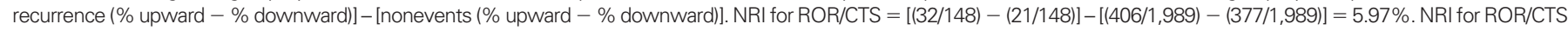
plus $\operatorname{ROR}=[(14 / 148)-(3 / 148)]-[(123 / 1,989)-(161 / 1,989)]=9.34 \%$. 